\title{
ANOSMIA: DESCRIÇÃO DESTA CONDIÇÃO POR PROFISSIONAIS DE SAÚDE E RELATOS DE PESSOAS QUE CONVIVEM COM A CONDIÇÃO
}

\section{ANOSMIA: DESCRIPTION OF THIS CONDITION BY HEALTH PROFESSIONALS AND REPORTS FROM PEOPLE WHO LIVE WITH THE CONDITION}

\author{
Hortência Gueve da Fonseca ${ }^{1} *$ Edmara Chaves Costa $^{2}$
}

\section{RESUMO}

Objetivo: Essa pesquisa dedicou-se qualitativamente, apreender o conhecimento dos profissionais de saúde de uma unidade básica de saúde do maciço de Baturité sobre a anosmia e relato de pessoas que convivem com essa condição. Métodos: A coleta de dados com os profissionais de saúde foi feita nas dependências da unidade de saúde, seguindo todas as medidas preventivas contra Covid-19, por meio de um roteiro com questões de caráter aberto, por outro lado, a coleta dos relatos dos indivíduos que vivem com anosmia foi feita por meio de um aplicativo da rede social (WhatsApp®). Resultados: Participaram nove profissionais da saúde $(n=09)$ e oito pessoas que convivem com anosmia $(n=8)$. As falas apreendidas da entrevista com os profissionais de saúde foram utilizadas para complementar a abordagem da temática pelas pessoas que convivem com anosmia e as representações das entrevistas com as pessoas que convivem com anosmia foram distribuídas em seis categorias: anosmia versus paladar; interpretação do odor; sentimento em relação a anosmia; constrangimento/vergonha/medo/enfrentamento; itinerário diagnóstico; descrença familiar/sofrimento e percepção de riscos associados a anosmia. Considerações finais: Da entrevista com os profissionais de saúde, a maioria demonstrou conhecimento da causa e no que concerne as pessoas que convivem com a condição, foi observado sentimentos positivos e otimistas como forma de enfrentamento à condição, mas também sentimentos negativos como medo, vergonha, constrangimento e ansiedade que servem de obstáculo para busca ao auxílio de profissionais especializados e de interação social.

Palavras-chave: Anosmia; Conhecimento; Relato.

\begin{abstract}
Objective: This research was qualitatively dedicated to apprehending the knowledge of health professionals from a basic health unit in the Baturité massif about anosmia and reports of people living with this condition. Methods: Data collection with health professionals was carried out on the premises of the health unit, following all preventive measures against Covid-19, through a script with open questions, on the other hand, the collection of reports from the individuals living with anosmia was made through a social network application (WhatsApp $\square$ ). Results: Nine health professionals $(n=09)$ and eight people living with anosmia $(n=8)$ participated in the study. The lines seized from the interviews with health professionals were used to complement the approach to the theme by people living with anosmia and representations of the interviews with people living with anosmia were distributed into six categories: anosmia versus taste; odor interpretation; feeling about anosmia; embarrassment/shame/fear/confrontation; diagnostic itinerary; family disbelief/suffering and perception of risks associated with anosmia. Final considerations: From the interview with health professionals, most demonstrated knowledge of the cause and, about people living with the condition, positive and optimistic feelings were observed as a way of coping with the condition, but also negative feelings such as fear, shame, embarrassment, and anxiety that serve as an obstacle to seeking help from specialized professionals and social interaction.
\end{abstract}

Keywords: Anosmia; Knowledge; Report.

\footnotetext{
1 Graduada em Enfermagem -Universidade da Integração Internacional da Lusofonia Afro-Brasileira. Pós-graduanda em Especialização em Atendimento Psicossocial á Vítimas de Violência-Universidade Federal de São Carlos. São Carlos/Brasil. ORCID: https://orcid.org/0000-0001-9712-8008

2 Doutora em Ciências Veterinárias pela Universidade Estadual do Ceará. Professora do Magistério Superior-Adjunto IVUniversidade da Integração Internacional da Lusofonia Afro-Brasileira. Fortaleza/Brasil. ORCID: https://orcid.org/0000-0003-0007$\underline{6681}$
} 


\section{INTRODUÇÃO}

O olfato é uma função sensorial importante para funções básicas como orientação, alimentação, reconhecimento de perigo e socialização. A palavra anosmia é subdividida em duas partes: " $a$ " que significa sem e "nosmia" (1). Nesse sentido, anosmia se caracteriza pela ausência da sensação olfativa e essa ausência pode ser congênita ou adquirida.

A congênita é a condição em que há ausência do olfato ao nascer devido algum tipo de distúrbio genético e a adquirida é originada a partir de sequelas de uma infecção, lesões nos neurônios sensitivos do olfato, doenças nasais, trauma na cabeça e uso de algumas toxinas. Há 3 tipos de anosmia: anosmia completa, caracterizada pela perda total das funções olfativas do indivíduo; a anosmia funcional, quando há limitação grave de função olfativa e a anosmia parcial quando há redução acentuada da sensibilidade a odores ${ }^{(1)}$.

Existem várias causas associadas ao distúrbio do olfato como: patologia sinusal (rinossinusite crônica e processos infecciosos); envelhecimento; traumas (atingimento intracraniano ou facial); doenças neurodegenerativas (doença de Parkinson, doença de Alzheimer, déficit cognitivo e esclerose múltipla); iatrogenia (medicamentos quimioterápicos, cirurgia de seios nasais, traqueostomia); doenças congênitas (síndrome de Turner e síndrome de Kallman); exposição a toxinas; deficiência nutricional (desnutrição e anemia perniciosa); HIV; transtornos psicológicos (esquizofrenia e depressão); cirurgia e idiopatia ${ }^{(1-2)}$.

Além disso, ${ }^{(3)}$ consideram que a perda da capacidade olfativa também tem impacto na higiene pessoal do indivíduo, pois, as pessoas podem exagerar na sua higiene pessoal, tomando banho várias vezes ao dia ou usar excessivamente o perfume.

Epidemiologicamente, a diminuição da função olfativa é muito comum, sobretudo na população idosa, estando presente em mais de 50\% dos indivíduos entre os 65 e os 80 anos, e em 62 a $80 \%$ acima dos 80 anos. Na Europa, cerca de $5 \%$ das pessoas sofrem de distúrbios olfativos e, não obstante, as disfunções olfativas são frequentemente subvalorizadas talvez porque a informação olfativa é processada em grande parte de forma inconsciente. Desse modo, a prevalência da perda olfativa autorrelatada está entre $14 \%$ e $15 \%$ dos casos, tendo a real prevalência destes distúrbios subestimada. Alguns autores apontam para uma prevalência de anosmia de uma em cada 200 pessoas ${ }^{(1)}$.

De acordo com ${ }^{(4)}$, o sentido do olfato é muito subestimado em importância no ser humano, apesar de sua utilidade não só em monitorar a entrada de agentes nocivos na via aérea superior como também em 
determinar o sabor e a palatabilidade de um alimento, por exemplo.

O atual contexto observado na literatura, relativo ao número de materiais produzidos e publicados sobre o estudo de doenças relacionadas com os sentidos humanos, remete-nos a encarar de forma diferenciada estas questões, principalmente entre os profissionais de saúde. Ainda são limitadas as pesquisas da área de saúde e, mais especificamente, que se situem na busca de informações referentes à anosmia.

Esta carência pode ter influência direta na eficácia e eficiência na prestação do cuidado destes casos por parte dos profissionais e, como diz ${ }^{(5)}$, a falta de conhecimento e treinamento dos profissionais de saúde na rotina diária sobre essa condição pode conduzir a erros de manejo e diagnóstico do distúrbio de olfato.

Nesta linha de ideia, a presente pesquisa é justificada pela preocupação em se conhecer mais sobre a anosmia, enfatizando o conhecimento e a experiência de profissionais de saúde. Por outro lado, apreender os relatos das pessoas que convivem com a condição, também se faz necessário para sustentar a pesquisa. Adicionalmente, o interesse nesse trabalho se explica pelo fato da pesquisadora conviver com esta condição e pelo reconhecimento da necessidade de ampliação e divulgação de informações relacionadas à anosmia. E as hipóteses que norteiam o desenvolvimento do trabalho são: 1- os profissionais apresentam conhecimento $\mathrm{e}$ experiência limitados quanto a essa condição; 2- as pessoas que vivem com anosmia enfrentam desajustes físicos e sociais no decorrer de suas vidas. $\mathrm{O}$ artigo tem como objetivo apreender o conhecimento de profissionais de saúde acerca da anosmia e relatos de indivíduos que convivem com a condição

\section{MÉTODOS}

Trata-se de um estudo do tipo exploratório, de abordagem qualitativa, conduzido no período de dezembro de 2020 com profissionais de saúde e pessoas que convivem com anosmia.

\section{Pesquisa com as pessoas que convivem com anosmia}

A coleta de dados acerca dos relatos de pessoas que convivem com essa condição, foi feita por meio de um aplicativo da rede social (WhatsApp ${ }^{\square}$ ).

A técnica de amostragem usada, foi a do tipo não probabilística, seguindo o modelo (bola de neve) "snowball" para as pessoas que convivem com anosmia, em função da disponibilidade de tempo deles, na qual cada participante indica novos participantes até que alcance o objetivo proposto ${ }^{(6)}$. Nesse sentido, a amostra foi composta por oito participantes $(n=8)$, sendo 
o quantitativo de pessoas acessadas a partir do retorno do contato por meio da rede social da pesquisadora.

Elegeu-se como critérios de inclusão: conviver com anosmia, ser maior de 18 anos, ter aparelho celular, computador ou tablet com conexão à internet e acesso ao aplicativo WhatsApp e e-mail pessoal; e como critérios de exclusão: ter algum tipo de limitação de comunicação, relatado previamente pelo participante no primeiro contato com a pesquisadora, que impeça sua manipulação da tecnologia; apresentar anosmia transitória ou passageira, relacionada a causas diversas, inclusive por COVID-19.

A comprovação da maioridade foi feita por envio da imagem do documento de identidade dos participantes, as limitações de comunicação foram questionadas diretamente aos participantes de modo que se fosse o caso, identificar doenças como Alzheimer, Parkinson e Síndrome de Down, por exemplo. Nos casos de anosmia recente relacionada a COVID-19, foi avaliada a condição com base na duração da ausência do sentido, considerando recente com relato por tempo inferior a um ano.

As etapas da pesquisa foram: divulgação de informações sobre a pesquisa por meio da rede social da pesquisadora, incluindo convite e solicitação de contato com pessoas dentro dos critérios de inclusão; retorno dos participantes e estabelecimento de contato pelo WhatsApp; comprovação da maioridade e esclarecimento dos objetivos da pesquisa; envio de TCLE para leitura e assinatura; início da entrevista por áudio; fim das entrevistas; análise dos dados obtidos. Essa entrevista teve como pergunta norteadora: "como é a sua convivência com essa condição?". A constatação de anosmia foi considerada com base no autorrelato e no contexto associado ao discurso do participante e no tempo de duração referido da ausência de olfato.

\section{Pesquisa com os profissionais de saúde}

A coleta de dados com os profissionais de saúde foi realizada nas dependências de uma unidade básica de saúde do Maciço de Baturité, considerando todas medidas de prevenção e proteção contra Covid-19 recomendada pela OMS.

Utilizou-se a técnica de amostragem intencional para a formação da amostra dos profissionais de saúde, sendo que a escolha dos participantes foi feita a partir do julgamento do próprio pesquisador, com base nos critérios pré-estabelecidos. A amostra foi composta por nove profissionais $(n=9)$ de saúde, que compõem o quadro da unidade, obedecendo ao critério de saturação teórica de dados, sendo considerada a saturação quando não se encontra nenhum elemento novo e deixa de ser necessário acrescentar informações, uma vez que não altera a compreensão do que está sendo estudado ${ }^{(7)}$. 
Foram instituídos os seguintes critérios de inclusão: estar regularmente vinculado/a à unidade de saúde, ter pelo menos seis meses de experiência profissional; e como critério de exclusão: estar em situação de férias, afastamento ou licença. A coleta de dados teve as seguintes etapas: esclarecimento sobre os objetivos da pesquisa; entrega de termo de consentimento livre e esclarecido (TCLE) para leitura e assinatura em caso de concordância; início da coleta de dado por meio de roteiro com questões de caráter aberto; fim da coleta de dados; análise dos dados obtidos.

O roteiro continha quatro questões para nortear o preenchimento deste pelos profissionais sendo elas: Já ouviu falar sobre anosmia? Se sim, o que sabe sobre esta condição?; Conhece ou já atendeu alguma pessoa que vive com esta condição? Qual seria a causa?; Qual(is) risco(s) pode(m) apresentar uma pessoa nesta condição?; Como um profissional de saúde poderia ajudar esse paciente?. Além disso, a idade, sexo, categoria profissional, tempo de trabalho e de formação, foram também incluídas no roteiro como forma de se identificar o perfil de cada participante.

\section{Organização e análise de dados}

Após conclusão das entrevistas com os profissionais bem como as pessoas que convivem com anosmia, foram feitas as transcrições integrais das gravações em áudio e das respostas obtidas no preenchimento do roteiro, de cada participante. A etapa da análise de dados foi realizada da seguinte forma: a pré-análise, no qual o material foi organizado compondo o corpus da pesquisa; a exploração do material e tratamento dos resultados ${ }^{(8)}$.

Depois de realizada a transcrição dos áudios e análise dos dados, as gravações foram mantidas salvas no computador do tipo notebook da pesquisadora e, após os quatro anos recomendados de guarda, para fins de revisão e comprovação formal da pesquisa, os arquivos serão eliminados permanentemente. Os dados obtidos foram organizados no Word versão 2010. Na sequência, foi realizada a análise qualitativa, obtendo-se as frequências das variáveis categóricas, padronizado pela contagem do número de palavras do corpus total em relação às categorias obtidas.

\section{Questões éticas}

Foram observados os princípios éticos da pesquisa científica, que visa preocupação com a dimensão ética, assegurando o caráter confidencial e a diminuição de prejuízo físico, financeiro ou emocional para o participante como regulamenta a Comissão Nacional de Ética e Pesquisa (CONEP). Essa pesquisa buscou minimizar os danos aos participantes e evitou os riscos previsíveis mesmo que categorizados como mínimos, no âmbito moral, social e psíquico, a curto e longo 
prazo, cumprindo a Resolução 466/12 do Conselho Nacional de Saúde. Riscos esses, tais como: incômodo; de cansaço; desconforto; constrangimento; tensão social ou mesmo no relacionamento com $\mathrm{o}$ pesquisador; limitações de acesso em relação a conexão da internet e estresse relacionado a recordação de experiências de vida negativas, amplificada pelo contexto da situação de distanciamento social relacionado a pandemia de COVID-19.

\section{Então para minimizar esses} riscos, teve-se como medida preventiva: a coleta dos dados em menor tempo possível; e, em caso de queda da conexão de internet, a suspensão momentânea da pesquisa, com previsão de retomada para o dia posterior ou outro dia que o participante designar, dentro do limite de tempo determinado para finalizar toda a pesquisa.

O projeto objeto do presente trabalho, foi submetido à apreciação pelo Comitê de Ética em Pesquisa da UNILAB, tendo sido aprovado, conforme CAAE 33428720.4.0000.5576 e $\mathrm{n}^{\mathrm{o}}$ do parecer
4.444.498. Foram garantidas a autonomia dos sujeitos, a não maleficência e a beneficência da pesquisa, preconizadas na Resolução 466/12 do Conselho Nacional de Saúde.

\section{RESULTADOS E DISCUSSÃO}

Dedica-se esse capítulo à análise dos conteúdos emergidos dos discursos dos participantes da pesquisa entrevistados acerca da convivência com a anosmia em suas dimensões qualitativas. Participaram dessa pesquisa, oito pessoas com anosmia de diferentes nacionalidades, sendo três de nacionalidade brasileira, duas de nacionalidade angolana, duas de nacionalidade santomense e uma de nacionalidade guineense, com idade compreendida entre 21 e 49 anos.

As representações serão discutidas a partir de seis categorias e seis subcategorias encontradas nas falas dos envolvidos na pesquisa com as pessoas que convivem com anosmia e serão complementadas com os discursos envolvidos a partir da pesquisa com os profissionais da saúde no decorrer do texto.

Quadro 1- Caracterização dos profissionais de saúde.

\begin{tabular}{|l|c|c|c|}
\hline \multicolumn{1}{|c|}{ Categoria Profissional } & Idade & $\begin{array}{c}\text { Tempo de } \\
\text { trabalho }\end{array}$ & Tempo de formado \\
\hline Médico & 59 anos & 25 anos & 20 anos \\
\hline Médico comunitária de & 37 anos & 04 anos & 06 anos \\
\hline $\begin{array}{l}\text { Agente } \\
\text { saúde (ACS) }\end{array}$ & - & 04 anos & 04 anos \\
\hline
\end{tabular}




\begin{tabular}{|l|c|c|c|}
\hline $\begin{array}{l}\text { Agente comunitária de } \\
\text { saúde }\end{array}$ & 34 anos & 04 anos e 06 meses & 08 anos \\
\hline Técnica de enfermagem & 49 anos & 20 anos & 25 anos \\
\hline Técnica de enfermagem & 60 anos & 10 anos & 30 anos \\
\hline Enfermeira & 24 anos & 01 ano e 08 meses & 01 ano e 08 meses \\
\hline Auxiliar de enfermagem & 49 anos & 19 anos & 15 anos \\
\hline Auxiliar de enfermagem & 53 anos & 02 anos & 20 anos \\
\hline
\end{tabular}

Fonte: Os autores

Destaca-se, de modo isolado, partindo da pesquisa com os profissionais de saúde que o conceito da temática questionado com base na seguinte pergunta: Pergunta 01 (PR01): já ouviu falar sobre anosmia? se sim, o que sabe sobre esta condição?, cinco dos nove participantes conceituaram de forma mais exata e próxima da realidade. Por outro lado, quatro dos nove participantes não souberam aprofundar a temática, portanto, esses participantes não se sentiram aptos para dar continuidade e responder as outras questões no roteiro da pesquisa.

Os participantes que não souberam responder as questões colocadas, pôde-se perceber um pequeno incomodo e ao mesmo tempo o interesse de pesquisar e buscar conhecimentos acerca do assunto, além disso, acredita-se que esse contato com o tema tenha sido uma experiência positiva.

Quadro 2-Distribuição das categorias e subcategorias emergidas dos discursos dos participantes da pesquisa - pessoas que vivem com anosmia. Redenção - CE, 2021.

\begin{tabular}{|c|c|c|}
\hline CATEgorias e SubCategorias & $\begin{array}{l}\text { UNIDADES DE } \\
\text { REGISTRO* }\end{array}$ & $\begin{array}{c}\text { PROPORÇÃO } \\
\text { [\%] }\end{array}$ \\
\hline CATEGORIA 1: ITINERÁRIO DIAGNÓSTICO & 1.240 & 39,1 \\
\hline $\begin{array}{l}\text { Subcategoria 1.1. Fatores etiológicos: infecções de vias } \\
\text { aéreas superiores; traumatismo craniano e uso irracional de } \\
\text { medicamentos } \\
\text { Subcategoria 1.2. Fatores etiológicos: idiopatia e genética }\end{array}$ & $\begin{array}{l}882 \\
358\end{array}$ & $\begin{array}{l}71,1 \\
28,9\end{array}$ \\
\hline CATEGORIA 2: SENTIMENTOS RELACIONADOS A ANOSMIA & 696 & 21,9 \\
\hline $\begin{array}{l}\text { Subcategoria 2.1. Negativo: } \\
\text { Constrangimento/Vergonha/Medo/Ansiedade } \\
\text { Subcategoria 2.2. Positivo: Enfrentamento }\end{array}$ & $\begin{array}{l}399 \\
297\end{array}$ & $\begin{array}{l}57,3 \\
42,7\end{array}$ \\
\hline $\begin{array}{l}\text { CATEGORIA 3: DESCRENÇA FAMILIAR/SOFRIMENTO } \\
\text { PSÍQUICO }\end{array}$ & 328 & 10,3 \\
\hline $\begin{array}{l}\text { CATEGORIA 4: PERCEPÇÃO DE RISCO ASSOCIADO A } \\
\text { ANOSMIA }\end{array}$ & 314 & 9,9 \\
\hline CATEgORIA 5: IMPACTO DA ANOSMIA SOBRE O PALADAR & 305 & 9,6 \\
\hline
\end{tabular}




\begin{tabular}{|l|c|c|}
\hline Subcategoria 5.1. Ausência de alteração do paladar & 168 & 55,1 \\
Subcategoria 5.2. Disgeusia & 137 & 44,9 \\
\hline CATEGORIA 6: INTERPRETAÇÃO DO ODOR & $\mathbf{2 9 2}$ & $\mathbf{9 , 2}$ \\
\hline
\end{tabular}

*Unidades de Registro: número de caracteres com espaço que compõem cada um dos segmentos dos discursos. Fonte: Os autores

\section{Categoria 1: Itinerário diagnóstico}

Essa categoria representa o caminho percorrido pelos indivíduos com anosmia desde a percepção da alteração no olfato até a busca ou não por auxílio médico. A trajetória clínica dos participantes se faz importante para compreender os desafios em suas relações com os serviços de saúde, seus fatores etiológicos bem como seus sentimentos em relação a anosmia, o que pode interferir na busca por auxílio de profissionais de saúde qualificados para a condição em causa.

Quadro 3- Verbalizações da categoria itinerário diagnóstico e suas subcategorias

\begin{tabular}{|l|c|c|}
\hline \multicolumn{1}{|c|}{ Unidade de Significação } & $\begin{array}{c}\text { Frequência } \\
\text { Absoluta }\end{array}$ & $\begin{array}{c}\text { Proporção } \\
\text { (\%) }\end{array}$ \\
\cline { 1 - 1 } $\begin{array}{l}\text { Categoria 1- Itinerário diagnóstico } \\
\text { Subcategoria 1: fatores etiológicos: infeções } \\
\text { de vias aéreas superiores, uso irracional de } \\
\text { medicamentos e traumatismo craniano }\end{array}$ & 882 & 71,0 \\
$\begin{array}{l}\text { Subcategoria 2: Fatores etiológicos: idiopatia } \\
\text { e genética }\end{array}$ & 358 & 29,0 \\
\hline \multicolumn{1}{|c|}{ Total } & 1.240 & 100,0 \\
\hline
\end{tabular}

Fonte: Os autores

- Subcategoria 1- fatores etiológicos: infeções de vias aéreas superiores, uso irracional de medicamentos e traumatismo craniano

Destaca-se a rinite (alérgica ou não) e a sinusite (de origem ocupacional ou não) como infeções de vias aéreas superiores mais comuns entre as pessoas. Essas infeções estão diretamente relacionadas a inalação direta de produtos tóxicos, alergênicos, medicamentos e metais que a depender da concentração e o tempo da exposição, podem provocar graves lesões nas vias aéreas ${ }^{(5)}$.

[...] trabalhei muito tempo em ambiente fechado, manipulava muito antibiótico, eu não sei se isso influenciou [...]. Era um ambiente fechado e eram antibióticos muito forte, tem que diluir, 
esperar um bom tempo para poder diluir aquele pó e tinha dia que não tinha EPI adequado para trabalhar (Participante 1, brasileira, 49 anos, sexo feminino).

[...] porque eu tenho rinite alérgica e rinite acaba causando essa anosmia [...] já é uma coisa digamos que crônico. [...] nunca fui pra consulta com otorrino porque sei que é rinite que causa isso (Participante 3, guineense, 25 anos, sexo feminino).

A causa foi o uso exagerado de descongestionante nasal, pois ele é vasoconstrictor e seu uso irracional causa problemas na mucosa nasal e até mesmo em casos mais graves problemas cardíacos (Participante 6, brasileiro, 25 anos, sexo masculino).

Segundo os autores ${ }^{(1-2)}$, há vários

fatores envolvidos em anosmia pós-trauma como lesão da cavidade nasal, do neuroepitélio ou do nervo olfativo, contusões, hemorragias em regiões cerebrais especialmente em situações de impacto frontal ou occipital. Um estudo demonstrou traumas na área frontal por vezes levam a perda do olfato, mas a anosmia completa é 5 vezes mais prevalente em pessoas com trauma na região occipital, podendo surgir logo após o trauma ou meses depois:

[...] não sei o que me levou a perder o olfato, mas tenho $90 \%$ de certeza que seja trauma pois já sofri muita queda e bati com a cabeça. Nunca tive rinite, sinusite, nada disso [...] (Participante 2, santomense, 25 anos, sexo feminino).

\section{- Subcategoria 2- fatores etiológicos: idiopatia e genética}

Por outro lado, existem casos em que não há razões suficiente para justificar a disfunção olfativa, o que se denomina de causa idiopática. É considerada anosmia congênita, a perda total de olfato desde o nascimento em indivíduos totalmente saudáveis ${ }^{(1)}$. É notável essas duas situações nas entrelinhas dos discursos a seguir:

[...] nunca fui pra médico para saber [...] porque sempre achei normal. Nem sei o que causou isso (Participante 4, santomense, 26 anos, sexo feminino).

Eu soube que não sinto cheiro a partir de 7 pra 8 meses da minha gestação e não procurei tratamento achando que quando eu estivesse no pós-parto ia recuperar meu olfato, mas só que até hoje, nada e Pedro já vai fazer 6 anos [...] eu não tenho certeza de nada que causou isso (Participante 5, brasileira, 48 anos, sexo feminino)

[...] eu nasci com esse problema [...] Além de mim, não tem mais ninguém da minha família com esse problema[...] (Participante 7, angolano, 24 anos, sexo masculino).

Não sei o que causou de concreto, porque aos 12 anos de idade, por vezes sentia cheiro, apesar de ser uma situação rara [...] nunca fui para consulta para saber o que causou isso[...] (Participante 8 , angolano, 21 anos, sexo masculino).

Como se pode observar nesses discursos, nem sempre a anosmia tem uma causa aparente e quando não se busca auxílio médico, a dúvida e a incerteza são ainda mais presentes. Além de que, a ajuda de profissionais de saúde, insere nos requisitos essenciais para a recuperação do olfato ou mesmo prevenir complicações futuras como ageusia. Os profissionais da saúde acrescentam mais sobre isso, como se observa a seguir, partindo do seguinte 
questionamento: PR04 Como um profissional de saúde poderia ajudar esse paciente?

Diagnóstico e tratamento precoce (Participante 1, Médico, 59 anos, sexo masculino).

Controle de sintomas, etiologia e orientações gerais (Participante 2, Médico, 37 anos, sexo masculino)

Procurar orientar o paciente a buscar ajuda médica (Participante 4, ACS, 34 anos, sexo feminino)

Escolhendo um bom perfume e dizendo que a comida não tá boa (Participante 5, Técnica de enfermagem, 49 anos, sexo feminino).

Encaminhar ao especialista e ajudá-lo a traçar estratégias para identificar certas situações de outras formas (Participante 7, Enfermeira, 24 anos, sexo feminino).

Levando ao médico (Participante 9, Auxiliar de enfermagem, 53 anos, sexo feminino).

No entanto, a maioria dos participantes, nunca buscou ajuda para tentar resolver a condição, alguns por falta de conhecimento sobre a condição e outros por vergonha. E os discursos de alguns profissionais de saúde corroboram com os discursos apresentados por pessoas que convivem com anosmia sobre a etiologia. Esse fato pode ser constatado pelos discursos a seguir, partindo do questionamento:" PR02. Conhece ou já atendeu algum portador desta condição? Qual seria a causa?"
Sim, com Covid-19 (Participante 1, Médico, 59 anos, sexo masculino).

Sim, atualmente número crescente por conta da pandemia do novo coronavírus (Participante 2, Médico, 37 anos, sexo masculino).

Sim, causa desconhecida (Participante 4, ACS, 34 anos, sexo feminino).

Irmão, por causa da rinite alérgica $(\mathrm{P} 5$, Técnica de enfermagem, 49 anos, sexo feminino).

Apesar de não ser o foco da pesquisa, dois profissionais citaram a Covid-19 como etiologia da anosmia. Então, pressupõe-se que essa citação se deve ao fato do que se vive atualmente no mundo, a pandemia do Covid19) na qual muitas pessoas têm-se queixado da perda do olfato e por ser um assunto que direta ou indiretamente nos cerca todos os dias, principalmente o profissional da saúde no exercício da sua profissão ${ }^{(9)}$.

\section{Categoria 2: Sentimentos em relação a anosmia}

Essa categoria emerge no que os participantes com anosmia são capazes de sentir perante a situação que vivenciam diariamente. O sentimento é algo intrínseco a todos os seres humanos podendo ser negativo ou positivo, além disso, pode se manifestar de diferentes formas dependendo de cada pessoa e o contexto em que se encontra inserido. 
Quadro 4: Verbalizações da categoria itinerário diagnóstico e suas subcategorias.

\begin{tabular}{|l|c|c|}
\hline \multicolumn{1}{|c|}{ Unidade de Significação } & \multirow{2}{*}{$\begin{array}{c}\text { Frequência } \\
\text { Absoluta }\end{array}$} & $\begin{array}{c}\text { Proporção } \\
\text { (\%) }\end{array}$ \\
\cline { 1 - 2 } Categoria 2 - Sentimentos em relação a anosmia & 399 & 57,3 \\
\cline { 1 - 2 } $\begin{array}{l}\text { Subcategoria 1: negativos: } \\
\text { constrangimento/vergonha/medo/ansiedade }\end{array}$ & 297 & 42,7 \\
\hline Subcategoria 2: positivo: enfrentamento & 696 & 100,0 \\
\hline
\end{tabular}

Fonte: Os autores

- Subcategoria 1-negativos: constrangimento/vergonha/medo/an siedade

Os sentimentos fazem parte de um estado de ânimo que surgem de acordo com os estímulos externos ou desencadeados por auto fracasso ao tentar cumprir metas e padrões e ao contrário dos sentimentos positivos, os sentimentos negativos provocam sensações desagradáveis as pessoas. A vergonha e o constrangimento são sentimentos que possuem características variadas e peculiares. Surgem em intensidades diferentes, podendo se manifestar de forma simples até atingir um grau complexo de sofrimento, que muitas das vezes se tornam irreversíveis. Esses sentimentos são inevitáveis, pois nos ajudam a proteger a nossa privacidade e intimidade simultaneamente, no entanto, são capazes de provocar bloqueios pontuais e graves dificuldades de desenvolvimento, de interação social, de autoconhecimento e de pedido de auxílio em situações que se necessita ${ }^{(10)}$.

[...] é assim eu me sinto até constrangida de por exemplo tô trabalhando, acontece assim um odor, um cheiro, alguma coisa, as pessoas perguntam tá sentindo esse cheiro? Entendeu? Eu me sinto constrangida em dizer que não estou sentindo aquele cheiro (Participante 1, brasileira, 49 anos, sexo feminino).

Já passei por muitos constrangimentos por conta disso, com os amigos, familiares e colegas de turma. [...] tenho vergonha de contar as pessoas que não sinto cheiro (Participante 2, santomense, 25 anos, sexo feminino).

Eu não procurei ajuda de médico por conta do receio também das pessoas saberem que não sinto. As vezes dá aquela vergonha né (Participante 5, brasileira, 48 anos, sexo feminino).

Eu não costumo falar, porém as vezes fico com receio de perceberem, e fico com vergonha também de estar utilizando muito perfume, as vezes eu chego perto e percebo olhares incomodados com cheiro 
(Participante 6, brasileiro, 25 anos, sexo masculino).

Às vezes me sinto constrangido (Participante 8, angolano, 21 anos, sexo masculino).

Outro sentimento relatado é o medo, caracterizado por uma emoção que tem sua causa direta e clara, por exemplo, o medo de morrer. O medo influencia no bem-estar físico e emocional do ser humano, encaixando-se nos padrões de ansiedade, uma vez que está relacionado a preocupação intensa, excessiva, persistente e medo de situações cotidianas já existentes ou que ainda não aconteceram ${ }^{(11)}$.

Outro fator importante é a insegurança para o futuro, pois o envelhecimento naturalmente reduz a percepção do olfato e isso me leva a crer que na terceira idade o meu problema se agrave. E então já vou me preparando psicologicamente para isso (Participante 6, brasileiro, 25 anos, sexo masculino).

Vivo com medo desta situação, porque pode acontecer uma tragédia por conta disso (Participante 8, angolano, 21 anos, sexo masculino).

Percebe-se a importância de se fazer uma gestão correta dos sentimentos negativos pois a frustação de não sentir cheiros, pode levar um indivíduo a perda de apetite e distúrbios alimentares, o que por fim poderá causar problemas na saúde física bem como psíquica, levando a uma situação mais grave de um transtorno depressivo ou ansioso.

\section{- Subcategoria 2 - positivo: enfrentamento}

Em contrapartida, alguns participantes relataram sentimentos positivos relacionados ao esforço cognitivo e comportamental que as pessoas demonstram para lidar com diferentes situações que vivenciam no dia a dia, e isso está voltado a aceitação das situações vivenciadas, como se pode ver nesses discursos.

Eu não sinto vergonha de falar para as pessoas, eu falo normalmente. Sou da opinião que você tem que avisar sim, pelo menos para as pessoas ao teu redor[...] (Participante 3, guineense, 25 anos, sexo feminino).

[...] Minha convivência com isso é normal $[. .$.$] quando compro creme ou$ outra coisa, não sinto o cheiro daquilo, mas eu uso mesmo assim. Não sinto vergonha em dizer[...] que não sinto cheiro, falo de boa (Participante 4, santomense, 26 anos, sexo feminino).

[...] Não sinto receio algum de contar as pessoas que não sinto cheiro porque eu aprendi a conviver e a me aceitar assim. Isso já faz parte de mim [...] (Participante 7, angolano, 24 anos, sexo masculino).

Não sinto vergonha de contar as pessoas que não sinto cheiro (Participante 8, angolano, 21 anos, sexo masculino).

Essas pessoas demonstraram positividade em suas falas, mesmo diante dessa condição. Inclusive, isso é uma das poucas formas de interiorizar que a sua 
condição não é motivo suficiente para se desistir de viver alegremente. E esse pensamento é essencial para que a pessoa viva uma vida de tranquilidade, sem preocupações excessivas que só trazem consequências para a saúde.

\section{Categoria 3: Descrença familiar/sofrimento psíquico}

Nessa categoria, os participantes destacaram sobre a reação de seus familiares e sendo a família a representatividade de união, segurança, amor, apoio, convivência, afeto e partilhas de sentimento, ela se destaca como imprescindível no processo de compreensão e aceitação da condição em que os participantes se encontram, que é de conviver com uma condição que para alguns, é desconhecida, o que, no entanto, gera muitas dúvidas.

A descrença familiar gera forte impacto na vida do indivíduo, podendo causar um forte sofrimento psíquico que em geral é consumado por um conjunto de ações manifestadas durante um curto ou longo período de tempo e isso influencia de modo significativo na forma como o indivíduo lidará com uma determinada situação, pois, acredita-se que quando em situações difíceis, o primeiro apoio com o qual o indivíduo pode contar é o de seus familiares ${ }^{(12)}$. As falas a seguir demonstram que nem sempre as famílias se apoiam, não por falta de amor, mas sim por falta de conhecimento da causa:
[...]Tive certeza de que eu não sentia cheiro aos 14 anos e meus pais também começaram a acreditar, mas antes disso sofri muito porque meus pais não acreditavam nisso, principalmente a minha mãe, por falta de conhecimento ou sei lá. Várias vezes a minha mãe me bateu porque eu deixei a comida queimar e eu sempre dizia pra ela que eu não sabia que estava queimando [...]Graças a Deus, um dia, os meus pais, estavam sentindo que tinha algo cheirando mal em casa[...]. Entraram no meu quarto[...], encontraram um rato morto bem debaixo da minha cama[...] Ficaram perplexos [...]. Pela manhã me chamaram, me contaram do acontecido e então me pediram pra fechar os olhos e fizeram uma série de testes comigo para ver se realmente eu não sentia cheiro [...]. Depois deste dia, começaram a me apoiar psicologicamente e me levaram pra fazer consultas[...] (Participante 2, santomense, 25 anos, sexo feminino).

Quando isso começou meus pais não deram muita credibilidade, pensaram que isso ia passar, mas não passou e fiquei assim... e até hoje acham isso engraçado[..] (Participante 4, santomense, 26 anos, sexo feminino)

Destaco, no entanto, o discurso da participante 2 como o de descrença familiar, porém em um âmbito extremo porque além da desconfiança, os seus pais a fizeram passar por provas para que assim ela pudesse realmente provar que não sente cheiro. Dá-se a entender que foi uma situação marcante em sua vida e que teve enorme significado que infelizmente, não retrata uma boa lembrança. Como referido em outras falas dessa mesma 
participante, ela sente vergonha da sua condição e analisando as falas dessa categoria, pode-se fazer uma relação de um dos fatores que desencadeou esse sentimento negativo.

\section{Categoria 4: Percepção de risco associado a anosmia}

Acredita-se que os indivíduos com anosmia têm vantagem, como por exemplo, de não ter que sentir cheiros desagradáveis, mas acontece que a anosmia afeta também negativamente a qualidade de vida dessas pessoas, sendo essencial para se detectar situações de perigos encontrados no cotidiano, como fumaça, vazamento de gás e comida estragada. Os indivíduos com anosmia têm três vezes mais probabilidade de estar em risco de experimentar um desses eventos acidentalmente em relação a indivíduos normósmicos. Também são obrigados a redobrar cuidados de higiene pessoal, podendo alguns exagerarem no uso dos produtos de forma inconsciente ${ }^{(3)}$.

Apesar da anosmia ser um tema pouco debatido em seu aspecto mais amplo, alguns discursos demonstram que também há riscos de desenvolvimento de algum distúrbio mental devido essa preocupação diária consigo mesmo porque ainda há casos em que o indivíduo apresenta dificuldade na compra de alguns produtos de higiene pessoal como perfume, desodorante, cremes corporais e não só. Então, é imprescindível que haja também acompanhamento psicológico adequado de forma individual, de modo que esses cuidados que são necessários não se tornem um fardo.

Quando estou cozinhando tenho que ficar direto olhando a panela para não correr o risco de queimar. Essa minha condição também me levou a ser muito mais rigorosa com minha higiene e do meu quarto e prestar mais atenção com o gás em casa[...] (Participante 2, santomense, 25 anos, sexo feminino).

[...]Eu lembro que as vezes meu irmão passava e percebia que o gás estava aberto e ele fechava, enquanto eu ali mesmo não dava conta [...] único problema que uma vez já passei é porque eu coloquei panela no fogo e tipo queimou a panela até sair fogo mesmo, quase incendiei uma casa (Participante 3, guineense, 25 anos, sexo feminino).

[...]teve um dia que tava tendo escapamento de gás, quando a casa já tava toda tomada foi que eu vim dar conta (Participante 5, brasileira, 48 anos, sexo feminino).

[...]tenho alguns problemas de convivência, como escolher um perfume, sentir o cheiro de uma comida queimada, de uma comida azeda (Participante 7, angolano, 24 anos, sexo masculino).

Corro risco de estar em uma situação de incêndio por exemplo, e eu não dar conta (Participante 8, angolano, 21 anos, sexo masculino).

Os discursos dos profissionais de saúde, reforçam sobre os riscos que essas pessoas enfrentam diariamente. 
Dependendo de como, pode dar até risco de morte associado a covid (Participante 1, Médico, 59 anos, sexo masculino).

Impacto na vida social e relação com alimentação (Participante 2, Médico, 37 anos, sexo masculino).

Risco de comer uma comida estragada (Participante 4, ACS, 34 anos, sexo feminino).

De comer comida estragada, usar perfume forte e risco de perda de paladar (Participante 5, Técnica de enfermagem, 49 anos, sexo feminino).

O olfato é um instinto protetor. A pessoa com essa condição corre o risco de passar por alguma situação de perigo onde possa ser identificado pelo olfato (incêndio, vazamento de gás) (P7, Enfermeira, 24 A, sexo feminino).
Alguns dos riscos apresentados pelos participantes se não forem evitados podem custar suas vidas, por isso, a importância de os profissionais de saúde em suas triagens avaliar o grau de comprometimento do olfato de cada indivíduo, compreender de forma holística a situação de cada um, de modo a dar orientações quanto a prevenção desses riscos.

\section{Categoria 5: Impacto da anosmia sobre o paladar}

Essa categoria representa a influência da anosmia sobre o paladar ao decorrer do tempo, partindo do autorrelato de alguns participantes, como consequência dessa condição.

Quadro 5: Verbalizações da categoria impacto da anosmia sobre o paladar e suas subcategorias

\begin{tabular}{|c|c|c|}
\hline Unidade de significação & \multirow{2}{*}{$\begin{array}{c}\text { Frequência } \\
\text { Absoluta }\end{array}$} & \multirow{2}{*}{$\begin{array}{c}\text { Proporção } \\
(\%)\end{array}$} \\
\hline Categoria 5- Impacto da anosmia sobre o paladar & & \\
\hline Subcategoria 1: Ausência de alteração do paladar & 168 & 55,1 \\
\hline Subcategoria 2: Disgeusia & 137 & 44,9 \\
\hline Total & 305 & 100,0 \\
\hline
\end{tabular}

Fonte: Os autores

- Subcategoria 1 - Ausência de alteração do paladar
Por meio de alguns discursos, percebe-se que nem todos os indivíduos com anosmia têm dificuldade em identificar o 
sabor dos alimentos e bebidas o que é de fato positivo, considerando que seja uma preocupação a menos, em relação aos outros participantes que enfrentam alteração no paladar como consequência da anosmia.

[...]O paladar é assim, eu sinto o sal, sinto o açúcar né, mas o olfato eu não tenho[...] (Participante 1, brasileira, 49 anos, sexo feminino).

[...]consigo diferenciar sabores de comida normalmente, bem, pelo menos até agora né. Eu gosto muito de cozinhar, fazer bolo, essas coisas né[...] (Participante 3, guineense, 25 anos, sexo feminino).

[...] consigo manejar alimento normalmente, graças a Deus. Sei diferenciar sabores também, então meu paladar ainda é aguçado. Não perdi o paladar por conta disso (Participante 4, santomense, 26 anos, sexo feminino).

Eu gosto um pouco de cozinhar e aprecio muito a comida[...] Meu paladar está bem fino mesmo (Participante 8, angolano, 21 anos, sexo masculino).

\section{Felizmente essas pessoas não}

tiveram o desprazer de perderem também o paladar, mas, por outro lado, existem pessoas em situações mais desafiadoras, que além de perderem o sentido olfato também têm dificuldades em identificar sabores de alimentos, o que influencia na execução de suas atividades diárias, como a de cozinhar.

\section{- Subcategoria 2- Disgeusia}

Nem todas as pessoas com anosmia têm o privilégio de permanecer com o seu paladar bem aguçado. Alguns perdem essa capacidade de saborear os alimentos e bebidas. $\mathrm{O}$ sentido olfato tem um importante papel no comportamento alimentar, inclusive para estimulação de apetite e para percepção do sabor durante o preparo ou consumo de qualquer alimento. Alguns estudos feitos, demonstraram que a diminuição ou a perda do paladar é uma das queixas comuns entre as pessoas que convivem com anosmia ${ }^{(13)}$. Essa alteração é notável nas entrelinhas dos autorrelatos a seguir:

[...] há um ano que venho percebendo que estou perdendo também o meu paladar[...] (Participante 2, santomense, 25 anos, sexo feminino).

Tenho dificuldade de manejar alimentos. Hoje em dia preciso da ajuda de pessoas para verificar os alimentos[...] me trazendo receio e me levando ao hábito de cheirar tudo que como, mesmo sabendo que não sinto cheiro. [...] desenvolvi hipertensão arterial sistêmica em virtude de sentir menos os sabores e com isso usar mais condimentos na preparação, como sal e açúcar para realçar o sabor (Participante 6, brasileiro, 25 anos, sexo masculino).

Destacando sobre a fala do participante 6, a perda do paladar também pode trazer consequências a saúde devido ao uso exagerado de certos produtos rotineiramente usados para preparo de alimentos. Por isso, é 
importante que haja uma rede de apoio, disposta a auxiliar as pessoas nessas situações de modo que se previna ou reduza possíveis patologias secundárias, como a de hipertensão arterial, por exemplo.

\section{Categoria 6: Interpretação do odor}

Essa categoria descreve o modo como os participantes interpretam o odor partindo de suas percepções no cotidiano, mesmo que não sinta realmente o cheiro em si. Algumas pessoas nascem sentindo cheiro e depois perdem a capacidade de sentir o cheiro então, tem-se uma memória olfativa ${ }^{(5)}$.

Então, se antes de perder o olfato, a pessoa gostava muito do café e quando beber novamente o café, ela imaginará que está sentindo esse cheiro dada a memória que tem guardada do café. Esse fato é relatado em um dos discursos:

[...] quando eu vou trocar um paciente, a fralda dele tá muito cheia, eu sinto o ácido queimando o meu nariz, não é queimando, incomodando assim de arder, mas eu sinto a presença dele entrando nas minhas fossas [...] algumas comidas, eu acredito que é porque tá armazenado no meu cérebro o sabor, eu ainda tenho prazer de comer porque eu lembro do sabor e boto na boca[...] (Participante 1, brasileira, 49 anos, sexo feminino).

[...] Às vezes quando faço café e dá pra sentir um cheirinho, é uma felicidade, acho que é porque já tenho cheiro de café gravado na minha memória, eu penso assim
(Participante 5, brasileira, 48 anos, sexo feminino).

Nessas falas é perceptível que nós como seres humanos temos a capacidade de associar os cheiros que sentimos e gerar memória no cérebro, portanto pode-se dizer que os odores têm poder de influenciar no comportamento humano. E essa memória se torna um importante instrumento de utilidade aos indivíduos que convivem com anosmia, auxiliando nesse processo de convivência com essa condição.

\section{CONSIDERAÇÕES FINAIS}

A partir dos resultados obtidos, considerou-se que a anosmia não é um tema totalmente desconhecido pelos profissionais da saúde, uma vez que esses profissionais da saúde que participaram da pesquisa demonstraram conhecimento sobre a condição.

É apenas um assunto pouco discutido no ambiente acadêmico durante a própria formação destes profissionais, além do fato de muitas pessoas que convivem com a condição não buscarem auxílio dos profissionais por vergonha e por falta de conhecimento. Portanto, a falta de busca por profissionais reduz as chances de terem experiências com esses casos e consequentemente abordarem muito pouco sobre o assunto quando lhes é questionado. 
Ressalta-se a importância da intervenção dos profissionais de saúde em relação a esta condição prevenindo complicações como ageusia e alguns destes profissionais relataram em seus discursos oferecer ajuda como: diagnóstico e tratamento precoce; controle de sintomas, etiologia e orientações gerais e traçando estratégias para identificar certas situações de perigo de outras formas. Situações essas como de vazamento de gás, incêndio e ingestão de comida estragada, perceptível nas entrelinhas dos discursos das pessoas que convivem com anosmia.

Percebeu-se também interesse desses profissionais de saúde em buscar e adquirir mais conhecimentos acerca do assunto. Essa pesquisa de certo modo, instigou a essas pessoas a se dispor a refletir sobre a temática e acredita-se que esse contato com o tema tenha sido uma experiência positiva, que poderá ser de grande utilidade para esses profissionais em suas práticas diárias.

Por outro lado, o caminho percorrido pelos indivíduos com anosmia desde a percepção da alteração no olfato até a busca ou não de auxílio médico, percebeu-se que alguns destes participantes não buscaram ajuda de profissionais por causa de sentimentos negativos como medo, constrangimento e vergonha. Mas foi observado também sentimentos positivos e otimistas por parte dessas pessoas como forma de enfretamento à condição, apesar de ser em menor proporção.

Além disso, alguns destes participantes demonstraram interesse em conhecer mais sobre a condição na qual convivem, fazendo questionamentos pontuais durante a pesquisa como forma de se interarem mais sobre.

Por meio dos discursos pôde-se perceber que a caminhada é leve para alguns e para outros não, uma vez que cada pessoa em sua particularidade lida com determinada situação de forma diferente. E essa particularidade deve ser respeitada e é entendida quando se vê nesta pesquisa que há participantes que olham para sua condição como uma situação passageira sem demonstrar sentimentos desesperadores, mas por outro lado há participantes que se sentem afetados de forma intensa, estando os dois grupos vivendo o mesmo acontecimento.

De modo geral, essa pesquisa apresentou limitações em relação a número reduzido de trabalhos recentes que abordem diretamente sobre o tema e pela dificuldade em recrutar as pessoas que convivem com anosmia, por isso, a amostra foi tão reduzida.

\section{REFERÊNCIAS}

1.Lopes TN, Costa CG, Perreira C, Duarte D, Paiva S, Oliveira C, et al. Distúrbios do olfato nos cuidados de saúde primários. Sociedade Gallega de Otorrinolaringologica. Matosinhos; 2018. 
2. Mohamamadi M. A Review on Anosmia. Research Journal of Pharmaceutical, Biological and Chemical Sciences. p.308313,2016 .

3.Gaines, A. Desordens olfativas. Am J Rhinol Allergy [Internet] 2013 may [acesso em $04 \quad$ out. 2020]27: S45 S47, 2013.Disponível em: https://journals.sagepub.com/doi/10.2500/ajra .2013 .27 .3898

4.Croy I, Nordin S, Hummel T. Distúrbios olfativos e qualidade de vida - uma revisão atualizada. Chem Senses [Internet] 2014 mar [acesso em 10 Jul de 2020];39(3):185-94. doi: 10.1093. Disponível em: https://pubmed.ncbi.nlm.nih.gov/24429163/.

5.Gregorio, LL, Caparroz F, Nunes LMA, Neves LR, Macoto EK. Distúrbios da olfação: estudo retrospectivo. Braz J Otorhinolaryngology. São Paulo [Internet] Jan/Fev 2014. [acesso em 10 Out 2020] vol.80 no.1. 2014. Disponível em :https://doi.org/10.5935/1808-8694.20140005

6.Vinuto, Juliana. A amostragem em bola de neve na pesquisa qualitativa: um debate em aberto. Campinas. 2014; 18 p.

7.Nascimento LCN, Souza TV, Oliveira ICS, Moraes JRMM, Aguiar RCB, Silva LF. Theoretical saturation in qualitative research: an experience report in interview with schoolchildren. Rev Bras Enferm [Internet] Jan./Febr.2018;71(1):228-33[cited 2020 out 04] Available from: http://dx.doi.org/10.1590/0034-7167-2016$\underline{0616 .}$

8.Bardin, Laurence. Análise de conteúdo. São Paulo: Edições 70; 2011. 229 p.

9. Kosugi EM, Lavinsky J, Romano AR, Fornazieri MA, Matsumoto GRL, Lessa MM, et al. Recuperação incompleta e tardia da perda súbita do olfato na COVID-19. Braz J Otorhinolaryngol [Internet] jul/ago.2020; 86:490-6. [Acesso em 04 out. 2020]. Disponível em: https://www.scielo.br/scielo.php?pid=S18088 6942020000400490\&script=sci_arttext\&tlng $=\mathrm{pt}$.

10.Starling ACL. A vergonha em psicanálise: da falha narcísica à transparência do eu. Dissertação [master's thesis] -Universidade de Brasília, Brasília; 2017. 104f.

11.Holanda VN, Bezzera AS, Tavares AR, Lima CIR, Mamede LTS, Araújo RLQ, et al. As bases biológicas do medo: uma revisão sistemática da literatura. Rev Interfa-ces [Internet] Set 2013; 1(3) [Acesso em 09 Fev 2020]

Disponível em:http://interfaces.leaosampaio.edu.br/index. php/revista-interfaces/article/view/419.

12.Brotto AM; Guimarães, ABP. A influência da família no tratamento de pacientes com doenças crônicas. Psicol. hosp. (São Paulo), São Paulo, v. 15, n. 1, p. 43-68, jan. 2017.

13. Boesveldt S, Postma EM, Boak D, Luessen AW, Schopf V, Mainland JD, et al. Anosmia-A Clinical Review. Chemical Senses. [Internet] Set 2017. Vol. 42, p.513523[cited 2020 July 10]. Available from: doi:10.1093/chemse/bjx025.

\section{Autor correspondente}

Hortência Gueve da Fonseca

Endereço: Rua Cézar Ricomi 33, São CarlosSão Paulo, Bairro Jardim Lutfalla, CEP: 13560-510

Telefone: +5585998688879

E-mail: hortenciafonseca2016@gmail.com

Submissão: 2021-06-30

Aprovado: 2021-09-07 